\title{
The Use of H5P in Teaching English
}

\author{
Julien Arief Wicaksono* \\ English Department \\ Politeknik Negeri Jember \\ Jember, Indonesia \\ julien_arief@polije.ac.id
}

\author{
Rimbi Budi Setiarini \\ Department of Management \\ STIE Mandala \\ Jember, Indonesia \\ rimbibudi@gmail.com \\ Adriadi Novawan \\ English Department \\ Politeknik Negeri Jember \\ Jember, Indonesia \\ novawan@polije.ac.id
}

\author{
Osamu Ikeda \\ Faculty of Language and Literature \\ Bunkyo University \\ Japan \\ nao6954hh@yahoo.co.jp
}

\begin{abstract}
H5P, HTML 5 Package, is a plugin for the existing publishing systems that helps the creator to make more interesting content like presentations, interactive videos, games, and quizzes. H5P has been used by teachers, practitioners, and content creators worldwide. This paper aims at observing the use of H5P in the English Language Teaching. It investigates the relation among the use of $\mathrm{H5P}$ in the teaching and learning process, the students' motivation, and their English skills development. It is based on a case study that was done in a university context by using observation, interviews, and document analysis. The participants were 19 students who were taking a Basic English course in the second semester. The data collected were corroborated with other evidence and theories, and analyzed to identify the effects of using it on the participants' motivation and English skills development. The findings show that the use of H5P in teaching English within 6 months had a relatively significant impact on students' motivation that can influence the effectiveness of their English skills development. Therefore, within the online and virtual English language teaching, the use of H5P can offer an exciting opportunity for the students to learn English in a way that is not monotonous but interesting, interactive, and engaging.
\end{abstract}

Keywords-English language teaching, H5P, motivation, English skills

\section{INTRODUCTION}

Teaching English for non-native speakers is challenging [1] in a way that cannot be generated from the L1 settings. The challenge is not only from the English language as a school subject for the learners, but also from the process of teaching in various classes. Many teachers and researchers claim that teaching English needs much effort in planning, applying, and evaluating it [2][3]. On the other hand, the students need motivation [4][5], not only intrinsic motivation, but also extrinsic motivation that can be boosted by the teacher in the process of teaching English [6][7]. One of the ways to boost motivation is making the process of teaching and learning English interesting [8][9].

The use of media in teaching and learning are really important. By using media in the teaching and learning process, the teacher will be equipped with "gears" to engage students in the learning process. Moreover, media can be used both in the situation where students are studying individually and working with other students in a group [10]. The appropriate selection and usage of media will give benefits for teaching and learning process, namely: 1) saving time; 2) increasing students' interest; 3) gaining students' attention; 4) clarifying ideas; 5) reinforcing concepts; 6) providing tone; 7) proving a point; and 8) assisting students in remembering the material [11].

The use of media in teaching and learning cannot be separated from Information and Communications Technology (ICT). ICT has been part of the education ecosystem thoroughly. Moreover, since the presence of Covid-19 pandemic, ICT has been showing its power in education, especially in the teaching and learning process. Most of the education institutions, especially universities, have only two choices in facing this pandemic, stopping their teaching and learning process temporarily, or continuing their teaching virtually with the ICT supports. A lot of them have chosen the second option to use ICT in their teaching and learning process [23].

There are abundant types of media used in teaching and learning processes which are based on ICT. Google classroom, Zoom, video, and WhatsApp are examples of common media used in teaching and learning processes during Covid-19 pandemic. However, some teachers might not be ready so they applied monotonous media in teaching [23]. A classical problem then arises. Getting bored usually comes when there is no variation in the use of media in teaching and learning processes. Therefore, teachers are expected to find and use various media when teaching.

$\mathrm{H} 5 \mathrm{P}$ is then chosen as an interesting alternative. H5P is a community driven project which provides free and adjustable sources to be used by everyone, especially teachers. H5P which is an acronym for HTML 5 Package, is a plugin for the existing publishing systems that enables the creator to make and share more interesting content like presentations, interactive videos, games, quizzes and more. Furthermore, $\mathrm{H} 5 \mathrm{P}$ is also defined as "an innovative, free, practical, and easyto-use tech software that English teachers and students can use when engaged in the teaching and learning English" [14]

There are a lot of activities available that can be chosen and applied through H5P. Based on the content types, there are at least 8 content types [17], as follows: 
- Text based content types

1. Fill the blanks: creating a task with missing words in a text

2. Drag the word: creating text-based drag and drop tasks

3. Mark the words: creating a task where users highlight words

4. Essay: creating Essay with instant feedback

- Question based content types

1. True-false question: creating True/False questions

2. Multiple choices: creating flexible multiple-choice questions

3. Single choice set: creating questions with one correct answer

4. Quiz: creating sequence of various question types

5. Personal quiz: creating personality quizzes

6. Summary: creating tasks with a list of statements.

- Image based content types

1. Drag \& drop: creating drag \& drop tasks with images

2. Find the hotspot: creating image hotspots for users to find

3. Find multiple hotspots: creating many hotspots for users to find

4. Image hotspot: creating an image with multiple image hotspots

5. Image sequencing: placing images in the correct order

6. Agamotto: creating a series of images and explanations

7. Collage: creating a collage of multiple images

8. Image slider: creating an image slider easily

9. Timeline: creating a timeline of events with multimedia

10. Image juxtaposition: creating interactive images

- Game based content types

1. Memory game: crating the classic image pairing game

2. Dialog cards: creating text based tuning cards

3. Flashcards: creating stylish and modern flashcards

4. Guess the answer: create an image with a question and answer

- Audio based content types

1. Audio: uploading an audio recording

2. Audio recorder: creating an audio recording

3. Speak the words: answering a question using your voice

4. Speak the words set: a series of questions answered by speech

- Complex content types

1. Interactive video: creating videos with enriched interactions

2. Course presentations: creating a presentation with interactive slides

3. Column: column layout for H5P content

4. Documentation tool: creating a form wizard with export

- Presentation content types

1. Iframe embedder: embedding from a URL or a set of files
2. Accordian: creating vertically stacked expandable items

3. Chart: generating bar and pie charts quickly

- New content types

1. Branching scenario: creating dilemmas and selfpaced learning

2. Virtual tour (360): creating 360 environments with interaction

3. Dictation: creating a dictation with instant feedback

4. Interactive book: (on process of building content type)

The various activities above are designed for engaging online learning while the teachers can assess the students' understanding of the course materials. When the learning process is engaging, the students are motivated to join and participate actively. Their active participation will in turn become the opportunity to develop their English skills.

The main purpose of using media in teaching and learning is to increase the students' motivation as mentioned above. The same point happens when the teachers use H5P in teaching English. It is also expected to increase the motivation as well as the students' engagement in the teaching and learning process. In particular context, $\mathrm{H} 5 \mathrm{P}$ is chosen mainly due to the capability to increase the students' learning experience and involvement throughout the course [15]. Then, the increased motivation is hopefully able to improve the achievement made by the students in English mastery.

A good achievement made by students is the goal of every course. There are researchers who claim that highly motivated students always have good achievements in English mastery [19][21]. Hitherto, other researches show that low motivated students can also have good achievements [16][18]. Those mysteries in relationships among the use of H5P in teaching, students' motivation, and students' achievement are going to be discussed in this paper.

\section{METHODS}

\section{A. Research Design}

The design of this research is qualitative. To be more specific, this study investigated the quality of relationships [12] among the use of H5P in teaching English, students' motivation and students' achievement in English mastery. By conducting this qualitative research, the researcher has no right to interrupt the existing setting of the teaching of Basic English. It means that this study was conducted in a natural setting and the researcher focused on the existing teaching and learning of Basic English course, especially the use of H5P in the teaching and learning process.

\section{B. Data Collection}

All of the data collection process was done from April to June 2020 in Politeknik Negeri Jember. 19 students from the IT department were occupied as the subject to be observed in this research. All of them were in the second semester and took a Basic English course in the 2019/2020 academic year.

The primary data of qualitative research are in the forms of words and performances [12]. Therefore, the researcher used instruments that could record words and performance, namely observation sheet, questionnaire, and documentation. 
The observation sheets were used to record the activity during the teaching and learning process. The questionnaire was addressed to all students to collect other data. Documents then used to support the data from observation and questionnaire.

In Indonesia, Covid-19 pandemic had forced all the classroom activities to be done in an online method since April 2020. Fortunately, Politeknik Negeri Jember has already used Moodle as its learning management system (LMS). However, this version of Moodle could not integrate H5P directly, but the lecturer could use embedded code to attach H5P activities in LMS. Because the lecturer had applied H5P in every meeting of the course, the observation was done in every meeting of the course from April to June 2020 in order to get a more comprehensive data. The researchers used a guideline in observing the activities to be more effective and focus on looking at the use of H5P and its impact on teaching English [20].

The questionnaire delivered to the students used both closed and open-ended questions. The reasons for using openended questions were to make the students felt comfortable to get as much information as possible that the students could describe [20]. There were 15 questions, which 10 were closed and 5 were open-ended questions. The questionnaire was using Google form.

The documents used in this study were teaching and learning documents, such as a list of the students, students' presence list, and students' score. The documents were used to get information about students' names, the presence of students in every meeting, and especially to identify the students' achievement. This study focused on English in general, consequently, the four skills of English were analyzed.

\section{FINDINGS AND DISCUSSION}

As shown by previous research and application by some teachers [13][14], there were some benefits and points to ponder in using H5P in teaching English. The following parts elaborate the findings of this study.

\section{A. Benefits in Using H5P in Teaching English}

Mohan states that there are eight benefits in using media in the teaching and learning process, namely: 1) saving time; 2) increasing students' interest; 3) gaining students' attention; 4) clarifying ideas; 5) reinforcing concepts; 6) providing tone; 7) proving a point; and 8) assisting students in remembering the material [11]. From analysis of the data, the use of H5P in teaching English has brought at least four benefits out of eight mentioned above. The benefits are increasing students' interest, gaining students' attention, reinforcing concepts, and assisting students in remembering the material.

The use of H5P in teaching English acted as an external stimulus which was intended to increase students' interest [22]. Making students interested in the material means having basic assets to start the students' engagement in the teaching and learning process. From the result of data analysis, it was known that almost $90 \%$ of students were interested in all H5P activities that had been attached. Only $10 \%$ of students said that it affected nothing. They stated that English was not their interest, so they argued that H5P activities gave no effect on making them interested in the material being taught.
The same thing happens in attention. H5P was used as an attention-getting media that was intended to focus and gain students' attention on material being exposed [22]. Gaining students' attention is needed to increase students' motivation [21]. The data analysis showed that almost $90 \%$ of students agreed that $\mathrm{H} 5 \mathrm{P}$ made them focus more on the material being delivered by the lecturer.

When students' interest and attention in the learning process are getting higher, it means that they have higher motivation in learning the materials [22]. However, there is a slight difference in numbers between the theory and the evidence in this study. About $90 \%$ of students agreed that H5P had made them interested as well as paid more attention to the material. Yet, only $74 \%$ of students claimed that their motivation was boosted by the use of H5P in teaching English.

About 16 out of 17 students (85\% of total students) who said that they were interested in all H5P activities got good scores in Basic English subject. So, there was a tendency that there was a positive relationship between motivation and achievement. However, this finding needs more evidence to support its tendency.

H5P activities had successfully reinforced concepts in every meeting done. $74 \%$ of students agreed that H5P activities had made the concepts of the course in every meeting easier to be caught. They argued that H5P activities were easier to follow and understand than just slideshow or text-based activities. Moreover, in assisting students in remembering the material, H5P activities were successful. $90 \%$ of the students agreed that H5P helped them to remember the materials in every meeting. Additionally, the students could "replay" the activities by themselves everywhere at any time. This could help students to re-memorize the material delivered in every meeting.

The two benefits above, because of using H5P in teaching English, gave effect on students' achievement. Also, about $85 \%$ of the students were having good scores in Basic English. Even $63 \%$ of students got A (81-100 from 100 scale scoring). So, it might be concluded that the use of H5P as media in teaching English has a positive impact on students' achievement in English mastery. Hence, other researches in the same topic are expected to give more evidence in claiming that the use of $\mathrm{H} 5 \mathrm{P}$ could directly give a positive impact to students' achievement.

Another benefit of using H5P in teaching English was its adaptability and the ease of application in Politeknik Negeri Jember' LMS. The lecturer just needed to copy the embedded code then attached it in the LMS. The only registered students could directly access the H5P activities from LMS. Most students were familiar with the interface and did not need any adaptation in accessing H5P in LMS.

\section{B. Points to Ponder}

The data analysis says that most of the students love to have $\mathrm{H} 5 \mathrm{P}$ in the teaching and learning process, especially video and presentation content based. With a creative modification, the video and presentation shared to the students will be so interactive and engaging. Thus, those will gain the students' interest and attention to the material being discussed. So, it is necessary to make the contents of H5P activity interactive and engaging. Moreover, some students like quizzes. They felt challenged and wanted to play more. 
Therefore, the lecturer should give a breakthrough in the appropriate time.

$\mathrm{H} 5 \mathrm{P}$ is a software that needs a computer to run. Almost all the activities in $\mathrm{H} 5 \mathrm{P}$ can be done in computer or smartphone, but sometimes the frame size needs to be adjusted to meet the smartphone screen size. Therefore, it is very crucial for the lecturer to make a well-planned activity or the lecturer can give direction whether the activity should be done by using computer, smartphone, or both. Surprisingly, all of the $\mathrm{H} 5 \mathrm{P}$ activities that had been applied by the lecturer were compatible with all students' smartphones.

The lack of internet connection may be the biggest barrier in applying H5P in teaching English. All the activities in H5P relies on internet connection, therefore the sufficient internet connection for not only lecturer but also students is a must to get students engagement and reach the successful teaching and learning process. From the data analysis, there were 5 students who were facing a difficulty in accessing H5P due to internet connection. The lecturer must be aware of this, especially when the lecturer uses an $\mathrm{H} 5 \mathrm{P}$ activity that requires a big amount of internet data. Because of Internet connection, the students' interest could be getting lower and might affect their achievement in English mastery. So, the lecturer should consider his students' internet connectivity before choosing, modifying, and applying H5P activities.

\section{CONCLUSION}

$\mathrm{H} 5 \mathrm{P}$ is an appropriate media which can be used as media in teaching English. H5P can increase students' interest and gain students' attention to the material being taught. It also promotes ease in reinforcing concepts and remembering the material being discussed since the students can "replay" the $\mathrm{H} 5 \mathrm{P}$ activities.

The result of data analysis says that the use of $\mathrm{H} 5 \mathrm{P}$ in teaching English had a significant impact on students' motivation and finally gave impact on students' achievement in English mastery. Yet, this finding needs more evidence to support the claim. Therefore, this study hopefully can be a reference for next research that observes the same topic.

From this study, so far, the use of H5P in teaching English gave ease and medium to interact for both lecturer and students. So, it is strongly recommended for teachers to use $\mathrm{H} 5 \mathrm{P}$ in teaching English, especially when the teaching and learning process is done virtually

\section{REFERENCES}

[1] F. Copland, S. Garton, and A. Burns, "Challenges in teaching English to young learners: Global perspectives and local realities", TESOL Quarterly, vol. 48, 2014.

[2] A. Derakhshan and M. Shirmohammadli, "The difficulties of teaching English language: The relationship between research and teaching”, International Journal of Linguistics, vol. 7, page. 102, 2015.
[3] Z. Akbari, "Current challenges in teaching/learning English for EFL learners: The case of junior high school and high school", Procedia Social and Behavioral Sciences, vol. 199, pp. 394 - 401, 2015.

[4] Z. Dörnyei, "Motivation in second and foreign language learning", Language Teaching, vol. 31(3), pp. 117-135, 1998

[5] G. Salehpour and A. Roohani, "Relationship between intrinsic/extrinsic motivation and L2 speaking skill among Iranian male and female EFL learners" Bellaterra Journal of Teaching \& Learning Language \& Literature, vol. 13(1), pp, 43-59, Feb-Mar 2020.

[6] R. Kamaruddin, S. Sha'ri, A. Ghazali, and R. Hamdan, "Intrinsic and extrinsic motivation as extralinguistics factors in second language learning among foreign students in five universities of Malaysia. Journal of US-China Public Administration, vol. 14, 2017

[7] T. Niazi and M. Zahid, "Intrinsic and extrinsic motivation for learning English as a second language (ESL) among pre university students of Pakistan", International Journal of Research and Innovation in Social Science, vol. 3, November 2019.

[8] H. F. Cheng and Z. Dörnyei, "The use of motivational strategies in language instruction: The case of EFL Teaching in Taiwan", Innovation in Language Learning and Teaching, vol. 1, pp. 153-174. 2007.

[9] H. Hassan, N. A. Hariri, and K. Khan, "Enhancing intrinsic motivation to learn in adults: empowering ESL students", International Journal of English Linguistics, vol. 10, 2020

[10] A. A. Naz and R. A. Akbar, "Use of media for effective instruction its importance: Some consideration", Journal of Elementary Education, vol. 18 pp. 35-40, January 2008

[11] T. Mohan, et al., "Communicating theory \& practice", Australia: Thomson, 2001.

[12] J. R. Fraenkel, N. E. Wallen, and H. H. Hyun, "How to design and evaluate research in education (8th edition)", NY: McGraw-Hill, 2011

[13] V. Sartor, "Keep your students connected and engaged with H5P”, EFL Magazine, July 2018.

[14] V. Sartor, "Using H5P + video to support English language learners", CALL Newsletter", August 2018.

[15] UNSW Sydney, "H5P activities".

[16] R. Fadhillah, "Learning motivation and English achievement of students at Politeknik Negeri Semarang Central Java", Jurnal Penelitian Humaniora, vol. 15, no. 2, pp. 89-98, August 2014.

[17] Moodle (Monash University Faculty of Arts), "Interactive content with H5P”,

[18] S. Orhan-Özen, "The effect of motivation on student achievement", in E. Karadağ (ed.), The factors effecting student achievement), Springer International Publishing, August 2017

[19] R. Steinmayr, A. F. Weidinger, M. Schwinger, and B. Spinath, "The importance of students' motivation for their academic achievement replicating and extending previous findings", Frontiers in Psychology, July 2019.

[20] L. Canals, "Instruments for gathering data", in E. Moore and M. Dooly (Eds), Qualitative approaches to research on plurilingual education pp. 390-401, Research-publishing.net, 2017

[21] M. M. Win, "Motivational factors to promote students' interest and involvement in teaching-learning English. PEOPLE: International Journal of Social Sciences", vol. 4(3) pp. 224-237, November 2018.

[22] E. Rosegard1 and J. Wilson, "Capturing students' attention: An empirical study", Journal of the Scholarship of Teaching and Learning, vol. 13, December 2013

[23] A. Schleicher, "The impact of COVID-19on education - Insights from Education at a Glance 2020", OECD, 2020. 